\title{
Water Infiltration and Moisture in Soils under Conservation and Conventional Agriculture in Agro-Ecological Zone IIa, Zambia
}

\section{Kjell B. Esser}

Norwegian University of Life Sciences, Faculty of Environmental Science and Natural Resource Management, P.O. Box 5003, 1433 Ås, Norway; kjell.esser@nmbu.no; Tel.: +47-976-81-277

Academic Editor: Ole Wendroth

Received: 23 February 2017; Accepted: 8 June 2017; Published: 10 June 2017

\begin{abstract}
Conservation agriculture is often presented as being 'climate smart' due to anticipated increases in soil moisture. The extent of enhanced water availability in farmers' fields is, however, poorly documented. This paper presents five data sets describing soil moisture in fields of small-scale conservation and conventional farmers in the Agro-ecological Zone IIa, Zambia. The data include (1) soil cover; (2) time required for visible soil surface saturation, ponding and initial runoff under artificial rainfall; (3) saturated water infiltration rates; (4) weekly soil moisture at six soil depths for two entire rain seasons; and (5) weekly rainfall in each field. Measurements were done for 15 pairs of comparable fields under conservation and conventional agriculture. Pairwise analysis showed significantly shorter time for surface saturation, ponding, and runoff in conservation fields compared to conventional fields. Saturated infiltration rates in riplines and basins of conservation fields were similar to rates in ploughed/hoed fields. Infiltration rates between riplines and between basins were 31-37\% lower than those in ploughed/hoed fields. Soil moisture in riplines and basins of conservation fields was higher by an average factor of 1.08 down to $40 \mathrm{~cm}$ soil depth, whereas it was lower by an average factor of 0.89 between plant rows compared to fields under conventional tillage. Based on 34,000 soil moisture measurements from 0 to $60 \mathrm{~cm}$ depth over two seasons, soils in conservation fields contained a weighted average of $18.2 \%$ (vol.) water compared to $19.9 \%$ (vol.) in conventional fields $(p<0.05)$. The results indicate that small-scale adopters of conservation agriculture are less 'climate smart' than conventional farmers in terms of water infiltration and soil moisture.
\end{abstract}

Keywords: climate smart; conservation agriculture; reduced tillage; conventional tillage; water infiltration; soil moisture; soil cover; ripping; planting basins

\section{Introduction}

Conservation agriculture, commonly defined as a combination of reduced tillage, residue retention, and crop rotation, has been shown to have positive effects on soil fertility, including water infiltration and soil moisture [1-3]. Partly due to higher water infiltration and availability in soils, conservation agriculture has been described as 'climate smart' [4].

Benefits of conservation agriculture have to a large extent been attributed to effects of soil cover [5-8]. Effects of reduced tillage alone have, however, been more variable and in some cases even negative [1,3]. For instance, Singh and Mahli [9] found higher bulk density and higher penetration resistance in the topsoil of a Black Chernozem after six years of no-till and no soil cover compared to conventional tillage, resulting in reduced infiltration rates. Similarly, Materechera and Mloza-Banda [10] observed higher topsoil penetration resistance and lower root length density in soils under minimum tillage (planting on 1- to 3-year old ridges) compared to conventional hoe tillage (annual ridging) in Malawi. 
Since soils in the subhumid and semiarid tropics "are more susceptible to surface crusting, hard-setting and compaction than soils in the northern latitudes" [11] largely due to intensive rainfall episodes, high iron hydroxide content, and low organic matter content, soil cover and surface crusting appear to have greater impacts on the performance of conservation agriculture in the tropics compared to other areas. Hence, studies on water infiltration and soil moisture under reduced tillage in temperate areas may not be directly relevant for the tropics.

Although higher crop yields under conservation agriculture are largely attributed to improved water infiltration and higher soil organic matter [12,13], adoption surveys of conservation agriculture are commonly based on tillage only [14]. The reason for linking adoption to tillage is that tillage is considered the most essential element of conservation agriculture. Tillage is also regarded as the indicator of adoption that is most easily recorded in large-scale surveys [14].

Nyanga [15] used any-sized area under minimum tillage as an indicator of adoption of conservation agriculture in Zambia regardless of its proportion of the farming areas. Crop rotation was not included because farmers already practiced rotation. Also, Nyanga [15] did not include retention of crop residues as an indicator due to common bush and cropland fires as well as communal cattle grazing on cropland in the dry season. Arslan et al. [16], however, used proportion of households practicing reduced tillage, proportion of cultivated land under reduced tillage and land under crop rotation as indicators of adoption.

Clearly, adoption surveys based on tillage alone may not provide reliable information about potential improvements in soil moisture, crop growth, and, ultimately, crop yield, particularly not for tropical soils. Therefore, the declared target of 350,000 adopters of conservation agriculture in Zambia by 2015 [17] appears to be a number of limited agro-economic significance unless there is evidence of on-farm improvements in water infiltration and soil moisture. So far, such evidence is lacking.

The objective of this study was to determine water infiltration and soil moisture in fields classified as being under conservation agriculture compared to fields under conventional agriculture in three areas in the Agro-ecological Zone IIa, Zambia. The study was part of the comprehensive Conservation Agriculture Research and Evaluation Programme 2012-2015, Zambia (CAREP).

\section{Results}

\subsection{Test for Comparability of Paired Fields}

Mean organic matter content and soil texture of the 15 pairs of studied soils are shown in Table 1. The test of similarity indicates that there was no systematic difference between the studied soils under conservation agriculture and conventional agriculture (Table 2). A pairwise comparison of water infiltration and soil moisture in the selected conservation and conventional fields appear, therefore, to be justified.

Table 1. Mean organic matter content $(\mathrm{OM})$ and particle-size distribution for fields studied for water infiltration and soil moisture.

\begin{tabular}{ccccccccc}
\hline & \multicolumn{3}{c}{ Conservation Fields } & \multicolumn{4}{c}{ Conventional Fields } \\
\hline & OM (\%) & Sand (\%) & Silt (\%) & Clay (\%) & OM (\%) & Sand (\%) & Silt (\%) & Clay (\%) \\
\hline Mumbwa & 1.65 & 66.0 & 26.4 & 7.6 & 1.74 & 59.2 & 30.4 & 10.4 \\
Monze & 1.87 & 75.6 & 16.4 & 8.0 & 1.50 & 79.0 & 14.4 & 6.6 \\
Chipata & 2.47 & 64.2 & 24.6 & 11.2 & 2.17 & 66.4 & 23.2 & 10.4 \\
\hline
\end{tabular}

Table 2. Mean pairwise ratios of organic matter content (OM) and texture for the conservation (CA) and conventional (CV) fields tested for water infiltration and soil moisture.

\begin{tabular}{ccccc}
\hline & OM & Sand & Silt & Clay \\
\hline Average of 15 CA/CV ratios & $1.09 \pm 0.33$ & $1.02 \pm 0.13$ & $1.10 \pm 0.67$ & $1.06 \pm 0.26$ \\
Student's $t$-test against expected mean of $1.00(p)$ & 0.314 & 0.523 & 0.585 & 0.395 \\
\hline
\end{tabular}




\subsection{Soil Cover/Crop Residues}

Mean soil cover was $17 \%$ for fields under conservation tillage and $11 \%$ for fields under conventional tillage. The numbers are not significantly different $(p=0.11)$.

\subsection{Artificial Rainfall}

Recorded data for time of surface saturation, time of ponding, and time of initial runoff according to pre-defined criteria are presented in Table 3. Surface saturation, ponding, and runoff occurred earlier on conservation-tilled fields compared to conventionally tilled fields. The differences are statistically significant with $p$ values at 0.0002 and 0.0004 .

Table 3. Time for surface saturation, ponding, and initial runoff (according to pre-defined criteria) for soils under conservation tillage and conventional tillage.

\begin{tabular}{ccccccc}
\hline \multirow{2}{*}{$\begin{array}{c}\text { Farmer } \\
\text { Pair No. }\end{array}$} & \multicolumn{3}{c}{ Conservation Tillage } & \multicolumn{3}{c}{ Conventional Tillage } \\
\cline { 2 - 6 } & Saturation & Ponding & Runoff & Saturation & Ponding & Runoff \\
\cline { 2 - 6 } & \multicolumn{7}{c}{ Time (min) } \\
\hline 1 & 3.68 & 5.85 & 7.93 & 8.53 & 12.63 & 18.38 \\
3 & 5.24 & 7.82 & 11.22 & 10.28 & 14.70 & 20.52 \\
4 & 4.77 & 8.04 & 10.13 & 11.71 & 17.54 & 23.02 \\
5 & 5.98 & 8.57 & 11.61 & 8.96 & 13.52 & 17.73 \\
6 & 8.65 & 10.52 & 13.80 & 10.39 & 13.26 & 20.67 \\
7 & 2.84 & 3.71 & 5.98 & 6.45 & 9.31 & 18.49 \\
8 & 9.08 & 13.09 & 17.98 & 20.67 & 26.94 & 32.17 \\
9 & 4.53 & 7.08 & 11.07 & 8.56 & 13.47 & $400^{*}$ \\
10 & 9.57 & 14.95 & 19.61 & 11.78 & 15.14 & 32.33 \\
11 & 5.33 & 10.67 & 17.88 & 5.75 & 8.28 & 14.83 \\
12 & 1.22 & 2.37 & 4.19 & 13.37 & 17.54 & $40 *$ \\
13 & 2.76 & 3.86 & 6.20 & 6.44 & 12.05 & 21.51 \\
14 & 2.79 & 4.14 & 5.81 & 8.15 & 10.59 & 19.88 \\
15 & 2.66 & 4.69 & 6.71 & 3.70 & 6.89 & 9.39 \\
Average & 4.03 & 7.67 & 14.09 & 5.39 & 8.32 & 14.91 \\
\hline Paired $t$-test $(p)$ & 4.87 & 7.54 & 10.95 & 9.34 & 13.35 & 22.92 \\
\hline \multicolumn{7}{c}{ * No runoff observed after 40 min at which time artificial rainfall was stopped. } \\
\hline
\end{tabular}

The data are presented graphically in Figure 1 in the form of pairwise conservation/conventional $(\mathrm{CA} / \mathrm{CV})$ ratios. Most ratios were within a range from 0.8 to 0.4 , which implies that it took between $25 \%$ and $150 \%$ longer time for saturation, ponding, and runoff to occur on conventionally tilled fields compared to conservation-tilled fields.

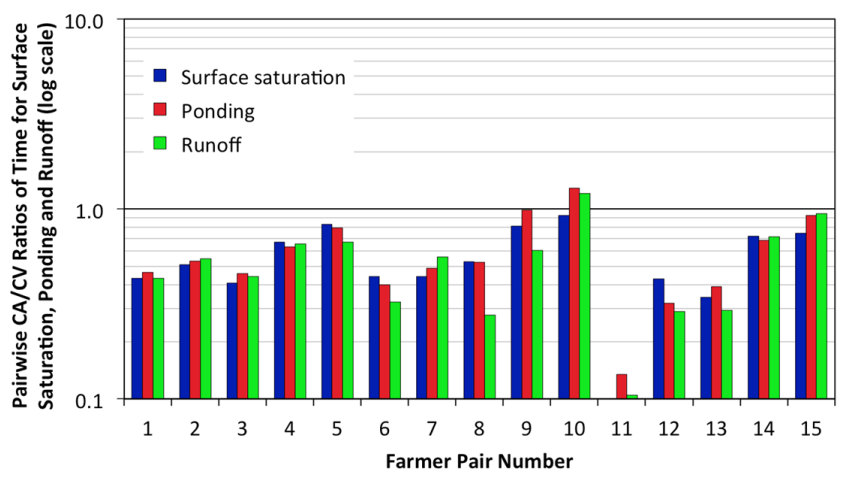

Figure 1. Pairwise ratios of time for initial surface saturation, ponding, and runoff for conservation and conventionally tilled fields. 


\subsection{Water Infiltration in Saturated Soil}

Mean water infiltration rates using ring infiltrometer after conversion to best-fit power functions are shown in Figure 2 in terms of infiltrated water per minute over $60 \mathrm{~min}$. For fields under conservation tillage, separate functions are shown for 'in riplines/basins' and 'between riplines/basins'. For conventional fields (ploughed and ridged), the results are shown as mean values across rows and interrows ('whole field'). The curves for 'conservation: in riplines/basins' and 'conventional: whole field' are almost identical, ranging from around $12 \mathrm{~mm} / \mathrm{min}$ at the start of the experiment to around $3.7 \mathrm{~mm} / \mathrm{min}$ at $60 \mathrm{~min}$ infiltration time (no statistical difference). Mean infiltration rates for 'conservation: between riplines/basins' were lower, i.e., $7.7 \mathrm{~mm} / \mathrm{min}$ at the start and decreasing to $2.6 \mathrm{~mm} / \mathrm{min}$ after $60 \mathrm{~min}$. The pairwise differences between 'conservation: between riplines/basins' and 'conventional: whole field' were statistically significant, with $p$ values ranging from 0.001 at the start of the experiment to 0.032 after $60 \mathrm{~min}$. A curve for 'conventional: between ridges' in ridged fields (four cases that are also included in the curve for 'conventional: whole field') is shown separately. The mean infiltration rate for the ridge depressions (between ridges) was not significantly different from their counterpart 'between riplines/basins' (Figure 2).

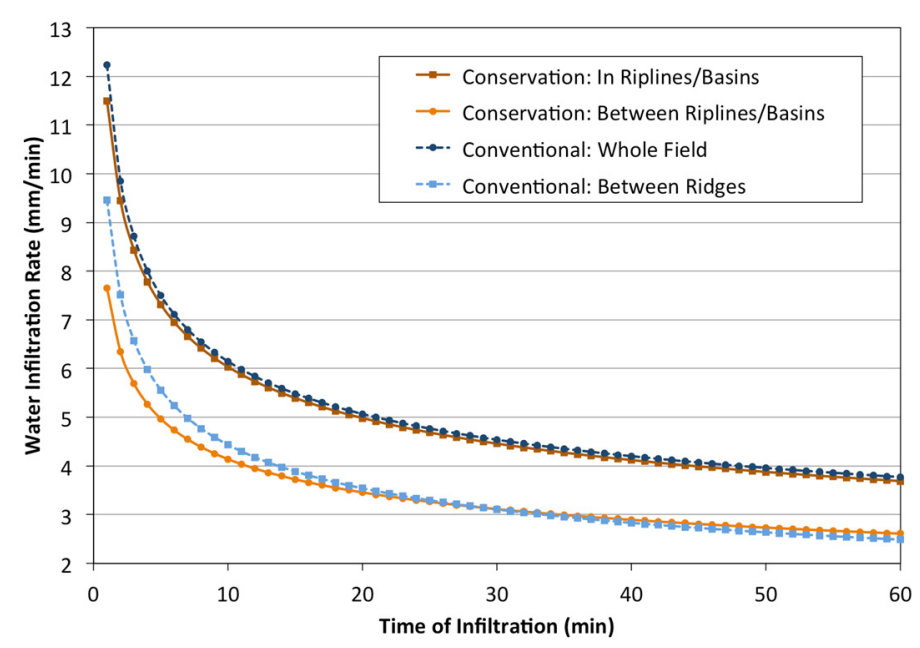

Figure 2. Mean water infiltration rates converted to best-fit power function for different field locations.

Since riplines constitute about $19 \%$ of the surface in ripped fields and basins constitute about $8 \%$ of the surface in fields with basins (based on average row distances of $80 \mathrm{~cm}$ between riplines and $75 \mathrm{~cm}$ between basin lines), the infiltration curves can be converted to weighted infiltration rates for whole fields, i.e., mean maximum rainfall without runoff for conservation tillage and conventional tillage (Figure 3). The mean weighted water infiltration rate for the conventionally tilled fields was $45 \%$ higher than for conservation-tilled fields at the start of the experiment and $36 \%$ higher after $60 \mathrm{~min}$ of infiltration. 


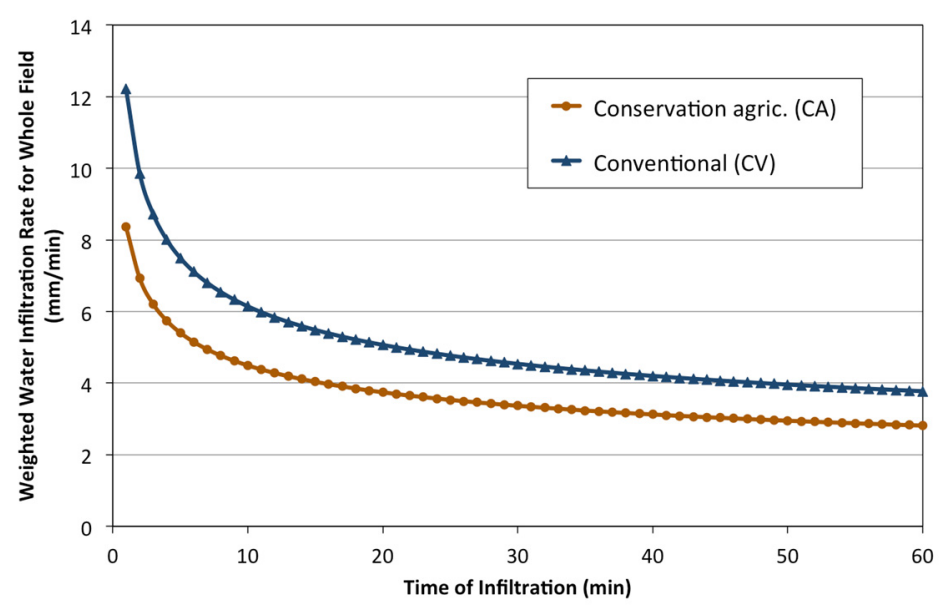

Figure 3. Mean weighted water infiltration rates for whole fields under conservation and conventional agriculture.

\subsection{Soil Moisture}

Mean pairwise ratios of soil moisture in riplines and basins of conservation fields (CA) relative to moisture in conventional fields (CV) at six soil depths in the 2013/14 and 2014/15 seasons are presented in Figure 4. Compared to conventional fields, soil moisture in conservation fields was higher in riplines and in basins ('in plant rows') by a mean factor of 1.08 down to $40 \mathrm{~cm}$ soil depth. The conservation-tilled soils contained less moisture between riplines and basins ('between rows') than the soil in conventional fields by a mean factor of 0.89 down to $40 \mathrm{~cm}$ depth. Seven of the data points in Figure 4 (marked by white stars) were significantly different from $1.0(p=0.002-0.045)$.

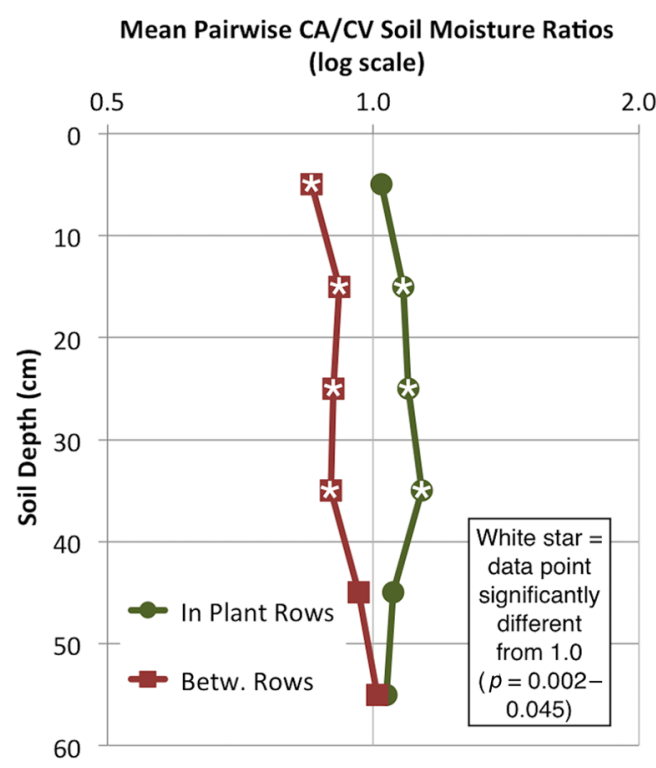

Figure 4. Mean pairwise soil moisture ratios $(\mathrm{CA} / \mathrm{CV})$ at six soil depths for two cropping seasons (2013/14 and 2014/15) in the Mumbwa, Monze, and Chipata areas.

Mean weekly pairwise ratios of soil moisture in riplines and basins of conservation fields relative to moisture in conventional fields during the 2014/15 cropping season are presented in Figure 5 together with mean weekly rainfall. Similarly, the mean pairwise ratios of soil moisture between riplines/basins of conservation fields and moisture in conventional fields are presented in Figure 6. 


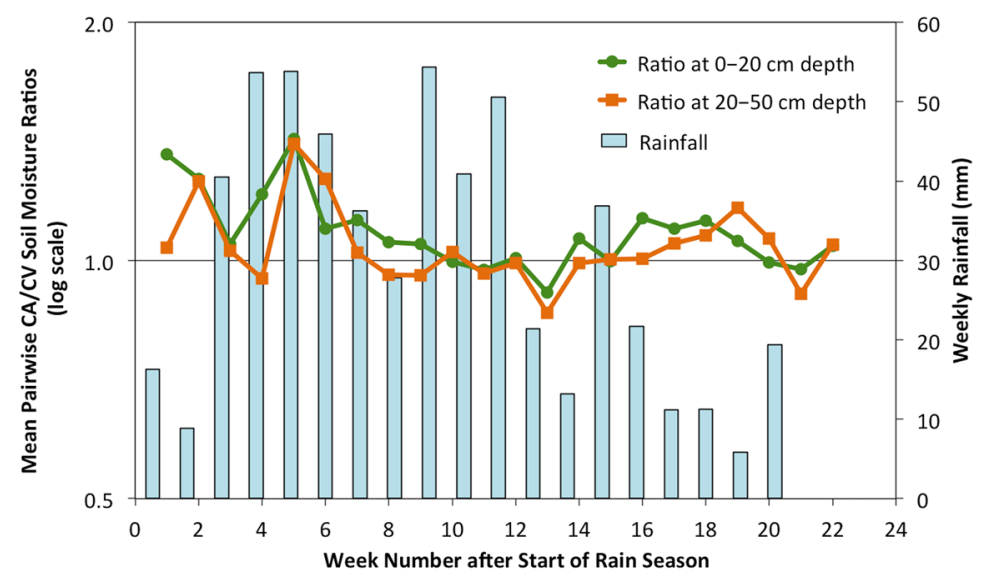

Figure 5. Mean weekly ratios of soil moisture in riplines/basins relative to moisture in paired ploughed/ridged fields (CA/CV) at two soil depths for the 2014/15 cropping season plus mean weekly rainfall in the Mumbwa, Monze, and Chipata areas.

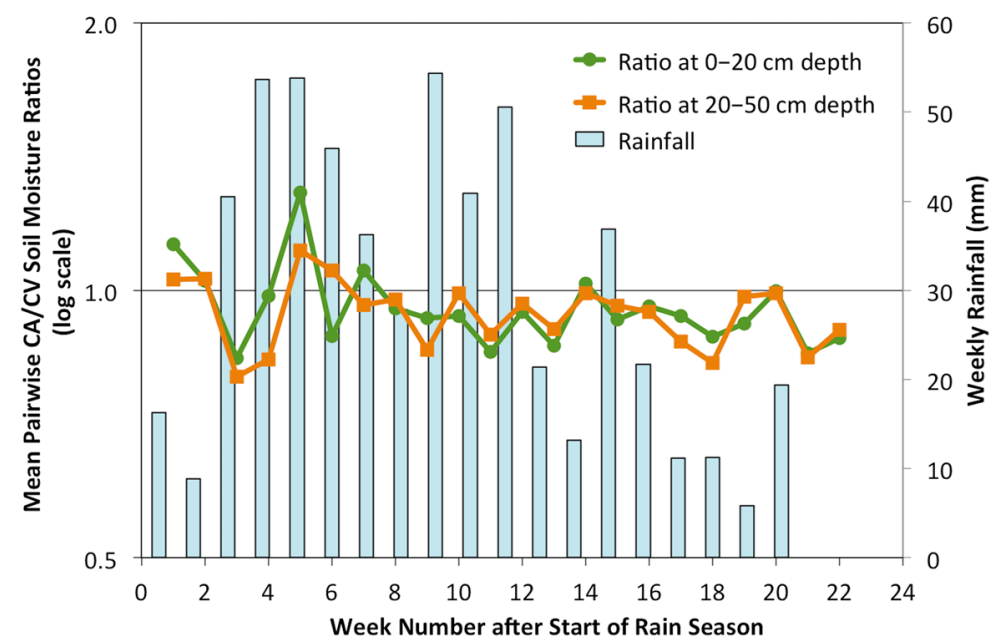

Figure 6. Mean weekly ratios of soil moisture between riplines/basins relative to moisture in paired ploughed/ridged fields (CA/CV) at two soil depths for the 2014/15 cropping season plus mean weekly rainfall in the Mumbwa, Monze, and Chipata areas.

Based on 34,000 soil moisture measurements over the 2013/14 and 2014/15 seasons, soils in conservation fields contained a weighted average of $18.2 \%$ water (vol.) in the top $60 \mathrm{~cm}$ (root zone) compared to $19.9 \%$ (vol.) in conventional fields $(p<0.05)$.

\section{Discussion}

The amounts of soil cover by plant residue were generally low in all fields. There was no significant difference in soil cover between fields under conservation and conventional tillage. Crop residues appeared to have been largely consumed by fire, cattle, and termites. By the time the infiltration tests were done, most of the residues that had been observed at the start of the season had mostly been consumed by termites. Therefore, plant residues did not interfere appreciably with the infiltration tests. Consequently, the observed differences in infiltration rates and soil moisture were primarily a function of soil tillage.

Conservation-tilled fields showed consistently shorter time for surface saturation, ponding, and runoff than conventional fields by an average of $48 \%$ (Figure 1). The results from the artificial rain test were, however, limited to the time of measurement. If a test had been done shortly after 
ploughing or mechanical weeding in conventional fields, the differences between conservation tillage and conventional tillage would probably have been larger than the recorded differences. On the other hand, if a test had been done towards the end of the cropping season (although impractical due to tall maize plants), the results would probably have shown smaller differences because sealing of soil surfaces by natural rainfall would have been more pronounced under both tillage methods. Also, a higher intensity of the artificial rainfall could potentially have reduced the differences in infiltration time between the two tillage methods.

Saturated infiltration rates were sensitive to soil tillage. Rates for 'in riplines' and 'in basins' were similar to those for ploughed and ridged fields. The results are reasonable since ripping and digging of basins have similar effects on soil porosity in the affected soil volume as ploughing.

Soil moisture in riplines and basins of conservation fields was higher by an average $8 \%$ down to $40 \mathrm{~cm}$ soil depth, whereas it was lower by an average $11 \%$ between plant rows compared to fields under conventional tillage. The variations in moisture were consistent with differences in infiltration rates.

Soil moisture in riplines and basins was noticeably higher than in ploughed/ridged fields early in the season (ratios above 1.0 in Figure 5). Riplines and basins appear to have acted as water collectors early in the season. In the case of relatively light rainfall events, collection of water in riplines and basins might be beneficial to crop growth. However, intense rainfall events occurring in the early parts of rain seasons $[18,19]$ may lead to ponding of riplines and basins, which in turn may harm seedlings and cause loss of applied nitrogen through denitrification [20]. From Week 8 into the cropping season, there were less differences or no differences between moisture in riplines/basins compared to ploughed/ridged fields (Figure 5).

Soil moisture between riplines/basins was generally lower than in ploughed/ridged fields (Figure 6). The larger soil volume 'between riplines/basins' compared to 'in riplines/basins' led, apparently, to the overall higher soil moisture for the whole season in the conventionally tilled fields $(19.9 \%)$ compared to the conservation tilled fields (18.2\%).

Theoretically, the lower values for soil moisture in conservation fields could potentially be due to better maize growth and higher consumption of water compared to the conventional fields. Yield data from the studied fields (not reported here) do not, however, support this theory [21].

The results from this study are supported by visual observations in the field by the research team and by testimonials by farmers [22]. Figure 7 illustrates a commonly observed situation where a conservation field shows signs of surface runoff from 'between riplines' and flooding 'in riplines', while a comparable conventional field shows signs of even infiltration across the fields, less runoff, and generally absence of flooding around seedlings.
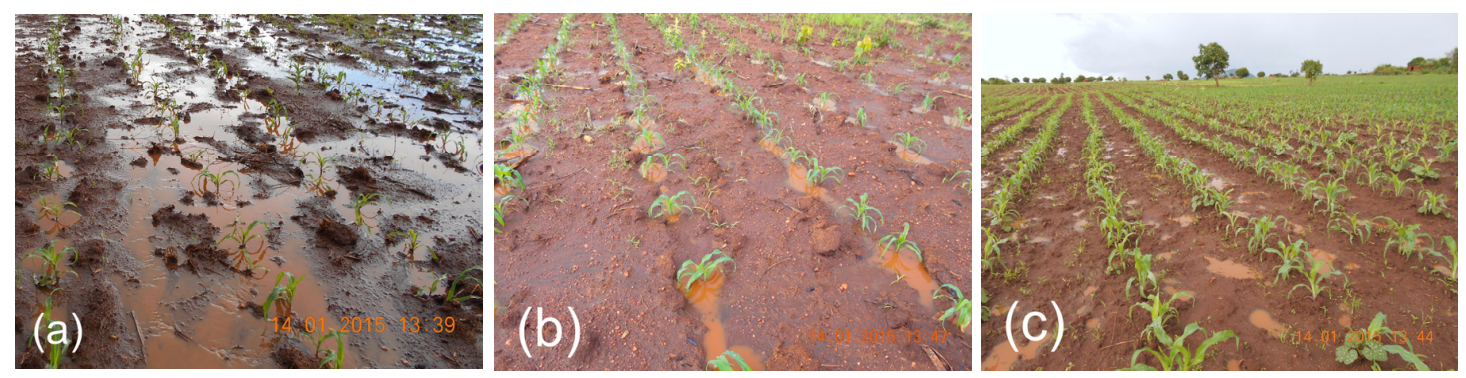

Figure 7. Example of water runoff between riplines (a); water puddles in riplines (b); and water puddles between plant rows without signs of runoff in a conventionally tilled field (c). The photos were taken $50 \mathrm{~m}$ and 5-8 min apart shortly after a rainstorm near Chipata (photo: K.B. Esser).

The results from this study support findings by Baudron et al. [23] who concluded that "conservation agriculture reduced water infiltration in wetter years" in Zimbabwe. Baudron et al. [23] also concluded that in dry years "a water harvesting effect was obtained with ploughing", which is also consistent with the results from the current study. 
This study was based on the agronomic management of some of the best trained, most experienced, and most dedicated small-scale conservation farmers in the study areas ('lead farmers' according to the Conservation Farming Unit) in order to quantify the upper realistic range of benefits in terms of soil water that can be expected from conservation agriculture promotion programmes in rural Zambia. Average adopters of conservation agriculture in Zambia most likely do not surpass the farmers recorded in this study.

\section{Materials and Methods}

\subsection{Study Areas}

Farming areas surrounding the towns of Mumbwa (Central Province), Monze (Southern Province), and Chipata (Eastern Province) in the Agro-ecological Zone IIa in Zambia (Figure 8) were selected on the basis of long-term history of conservation agriculture promotion as well as adoption by farmers. The Agro-ecological Zone IIa is characterized by an annual rainfall of $800-1000 \mathrm{~mm}$, moderately leached sandy loams, and a growing season of 100-140 days [24]. The cropping potential is classified as 'good', i.e., the best of Zambia's three agro-ecological zones [24]. Monze is the driest of the three areas, with annual precipitation of about $800 \mathrm{~mm}$ (recorded at Choma), followed by Mumbwa at $900 \mathrm{~mm}$, and Chipata at $1000 \mathrm{~mm}$ [25].

Soils in the Agro-Ecological Zone IIa are generally classified as Ferric/Orthic Acrisol (acid soils with subsoil accumulation of low-activity clay, developed in acid rocks) and Ferric Luvisol (less acid soils with subsoil accumulation of high-activity clay, developed in basic rocks). There are also some occurrences of Chromic Luvisol and Eutric Nitisol (deep, well-drained red soils with relatively high base saturation) [26]. Soils in the Mumbwa area appear to be more commonly of residual origin containing more clay than in the Mapanza area, where soils in large areas have formed in sandy river deposits. In the Chipata area, soils are largely of residual origin, but are younger and less leached compared to soils in the Mumbwa area due to a more hilly topography in the Chipata area.

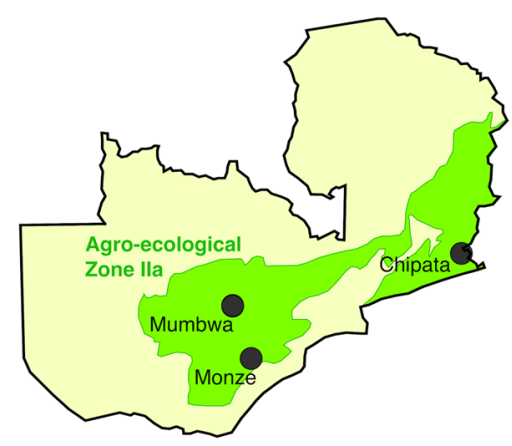

Figure 8. Map of Zambia showing Agro-ecological Zone IIa and approximate locations of Mumbwa, Monze, and Chipata study areas [27].

\subsection{Conservation Tillage Terminology}

Tillage under conservation agriculture in Zambia is normally done by ripping or digging of basins (Figure 9). For both tillage techniques, no soil movement is recommended during weeding or fertiliser application. However, farmers who make riplines and/or dig basins (i.e., classified as 'conservation farmers'), often use hand hoes, cultivators, or ploughs for weeding to the extent of full or near-full topsoil movement. Some farmers who rip may also use a plough to cover seeds and fertiliser and a harrow to break soil lumps after planting.

Conventional tillage applicable to small-scale farming in Zambia might be full or partial turnover of topsoil by plough or hand hoe with or without the formation of ridges or raised beds commonly followed by soil movement during weeding and covering of fertiliser (Figure 10). 
Farmers who plough do not necessarily move the whole topsoil. When weeds are not a major problem early in the cropping season, they may use the plough only to make planting furrows. Such plough furrows might be rather shallow, often no more than $5 \mathrm{~cm}$ deep. Shallow plough furrows may disturb less soil than tractor ripping, which is done to $15 \mathrm{~cm}$ depth.

During this study, the conservation and conventional farmers adhered to the teachings of their respective extension agents in conservation and conventional agriculture, i.e., ripping or basins without further soil movement during the cropping season and full tillage with subsequent soil movement during weeding and covering of fertiliser, respectively. In this report, the term 'conservation tillage' is used synonymously with 'minimum tillage' and 'reduced tillage'.
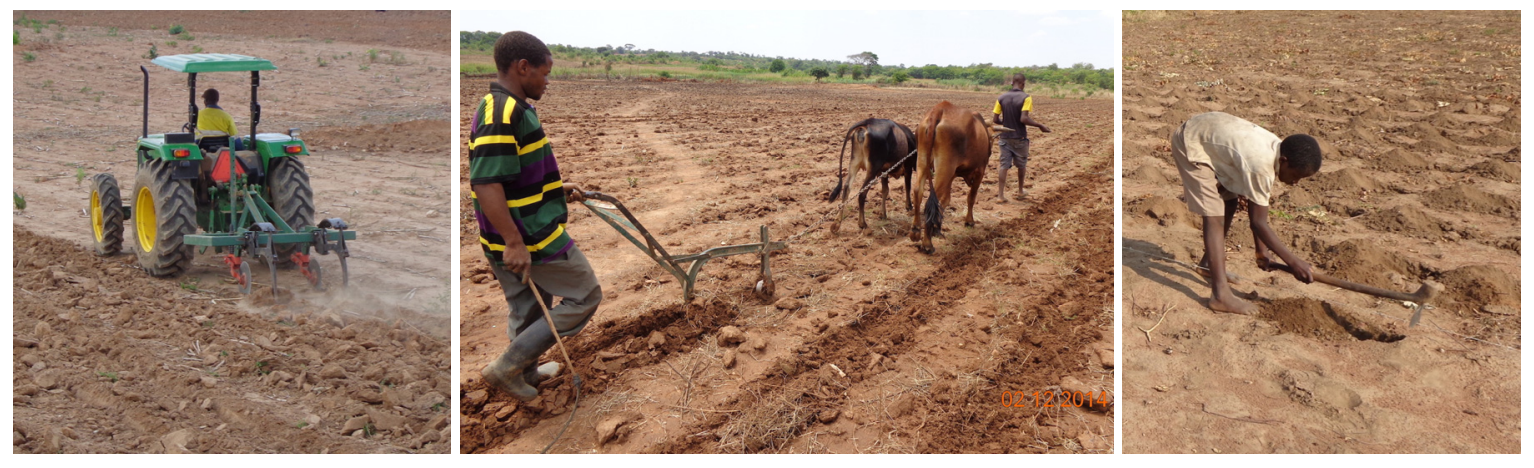

Figure 9. Conservation tillage: tractor ripping, ox ripping, and digging of planting basins (photo: K.B. Esser).
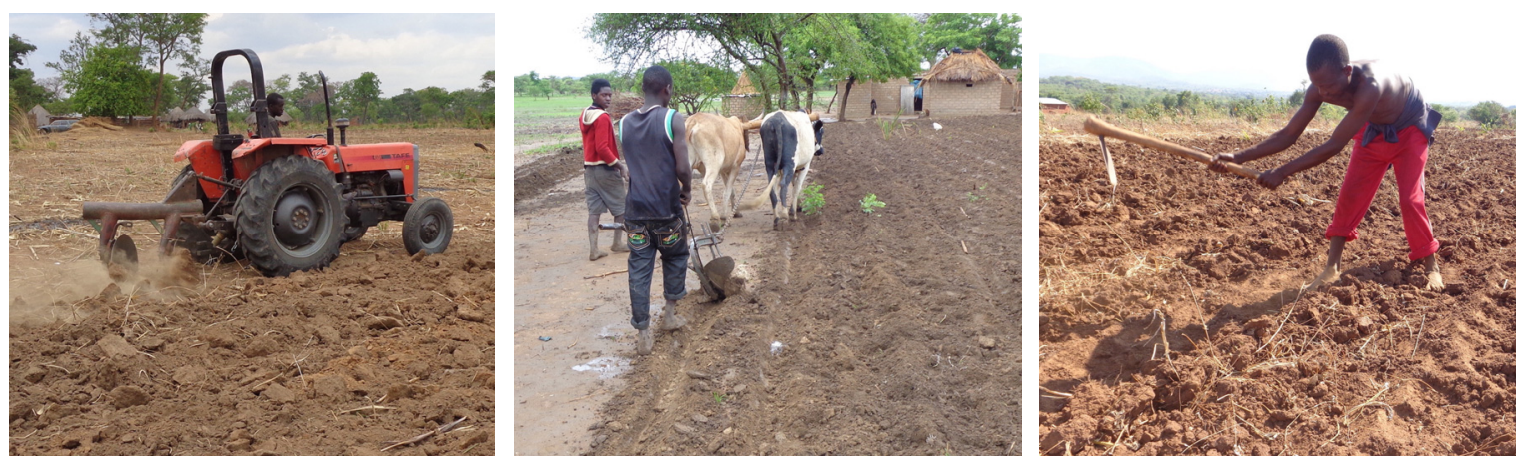

Figure 10. Conventional tillage: tractor disc ploughing, shallow ox ploughing, and hand-hoe ridging (photo: K.B. Esser).

\subsection{Farms, Farmers, and Fields}

Small-scale farms were selected within a radius of about $50 \mathrm{~km}$ from the three respective towns. Since agricultural development programmes commonly target leading community members as entry points for technology transfer [28], a random sampling of farmers would potentially lead to comparing fields managed by relatively more resourceful conservation farmers to fields managed by relatively less resourceful conventional farmers. To increase the likelihood of comparing fields of farmers with similar capabilities as well as comparing soils with similar qualities, homogeneous purposive sampling $[29,30]$ was applied. This was done by identifying a group of 15 conservation farmers with long experience in conservation farming (5-12 years) and proven dedication to the principles of conservation farming (preferably 'lead farmers' trained to train other farmers) from a list of recommended candidates provided by the Conservation Farming Unit. Ten of the conservation farmers practiced ripping either with hired tractor in the dry season and/or own oxen early in the rain season. In either case, they 
formed a 10-15 cm deep planting furrow. Five of the conservation farmers prepared planting basins according to received training, i.e., $15 \mathrm{~cm}$ wide, $30 \mathrm{~cm}$ long, and $15 \mathrm{~cm}$ deep basins using hand hoe.

For comparison, each of the 15 conservation farmers were paired with a farmer practicing conventional farming and fulfilling the following criteria to the extent possible: (1) similar resource status as the conservation farmers; (2) similar dedication to farming; and (3) cultivating a field close to the counterpart conservation field (preferably within $500 \mathrm{~m}$ ) with similar soil type, soil fertility, and slope. No predefined numerical cut-off criteria for the selection of conventional farmers were applied due to the complexity of parameters and challenges associated with measuring them. Similarities in dedication and resource status were judged subjectively through conversations with farmers and observations at their farmsteads. Similarity in soil type and slope was assessed by using soil auger and levelled yardstick, respectively.

\subsection{Field History}

Most fields had been cultivated for the last $30-40$ years. Tillage on conservation fields had been converted from ploughing or hoeing (conventional tillage) to either ripping or basins (conservation tillage) in the last 5-12 years. Riplines and basins had been reopened every season leaving the soil in-between untilled since the conversion of tillage method. The conventionally tilled fields had been cultivated by ox-drawn plough or hand hoe (ridging) since the start of cultivation. None of the soils had cultivation-induced hardpans (plough pans) that could impede water infiltration [31]. All fields were planted with maize (Zea mays L.) during the two-year study.

\subsection{Test for Comparability of Fields}

Since water infiltration and soil moisture are sensitive to organic matter content and particle-size distribution, a test for pairwise comparability between the conservation and conventionally tilled soils was performed. The test for pairwise similarity was done by calculating the pairwise ratios of values for organic matter and particle-size distribution for conservation fields relative to the values for conventional fields and testing for the probability of ratios being equal to 1.0. Organic matter content and particle-size distribution were analysed by the Service Laboratory, Department of Soil Science, University of Zambia [32].

\subsection{Field Measurements}

Five data sets were collected for each of the 30 selected fields:

(1) Extent of soil cover at the start of the cropping season.

(2) Soil surface infiltration under artificial rain by recording time for: (a) start of soil surface saturation; (b) start of ponding; and (c) start of runoff.

(3) Water infiltration using ring infiltrometer in plant rows and between plant rows for each tillage method, i.e., (a) in riplines (in spots without plants); (b) between riplines; (c) in basins (without plants); (d) between basin rows; (e) on ridges (in spots without plants); (f) in ridge depressions; and $(\mathrm{g})$ in ploughed/ridged fields (in and between rows).

(4) Soil moisture at six soil depths using a calibrated ohmmeter in plant rows and between plant rows for each tillage method, i.e., (a) in riplines; (b) in basins; (c) between riplines; (d) between basin rows; (e) in ridge depressions; (f) on ridges; and (g) in ploughed/ridged fields.

(5) Weekly rainfall.

Data collection sites for soil cover, infiltration, and moisture measurements were selected within fields on the basis of a combination of homogeneous and typical sampling [29], i.e., a purposive sampling technique minimizing variations in factors other than those under investigation by seeking comparable, normal cases. First, depending on the number of replicas, each field was divided into three or four parts with typically good, medium, and poor growth while avoiding excessively poor parts. Since purposive sampling is prone to researcher bias, measurement sites within fields were 
followed by a semi-random selection procedure. From the centre of each of the identified parts, five steps were taken along plant rows towards the nearest field edge followed by five steps across rows towards the field centre. The procedure for semi-random site selection was modified to ten steps when necessary to avoid microsites with abnormal growth or soil conditions.

Soil cover by plant residues was estimated early in the cropping season for 2013/14 and 2014/15 by using a $60 \mathrm{~cm} \times 80 \mathrm{~cm}$ frame divided by strings into $10 \mathrm{~cm} \times 10 \mathrm{~cm}$ squares. With three replicas, the frame was place on the ground, and the number of crosslines covering plant residues were counted and then divided by the total number of 35 crosslines. The measurement provided data for proportion of the land surface that were covered by plant residue, but did not capture the thickness of the residue.

Infiltration tests with artificial rain were conducted in the early part of the cropping season for 2014/15 after germination, but before the maize plants were large enough to obstruct the measurements. Artificial rain was sprayed over a circle with diameter of about $4.5 \mathrm{~m}$ from a fine-drop sprayer mounted on a tripod with the nozzle placed $1.0 \mathrm{~m}$ above the ground. The rainfall intensity was $18 \mathrm{~mm} / \mathrm{min}$, which is a fairly low rate compared to common rainstorms in the area. A low rate was chosen to obtain reasonable measurement separation for different soil types and tillage methods. On the other hand, the selected rainfall rate was too low to create runoff in two of the fields after $40 \mathrm{~min}$ (both under conventional tillage). In these cases, the time for runoff was arbitrarily set to $40 \mathrm{~min}$ for the purpose of calculations. Time of surface saturation was defined as the time from the start of rainfall until at least two spots of minimum $50 \mathrm{~cm} \times 50 \mathrm{~cm}$ showed a shiny, wet surface. Time of ponding was defined as the time of formation of two $10 \mathrm{~cm} \times 10 \mathrm{~cm}$ free water bodies unaffected by drips from plants. Time of runoff was defined as the time when a minimum of two moving bodies of water flowed a distance of at least $20 \mathrm{~cm}$. Despite quantitative definitions, measurements were to some extent subjective. To minimize the risk of systematic errors in time recordings, the same person (the author) made all time readings. Measurements under rainfall simulation were made with three replicas.

Ring infiltration measurements were done when the maize plants were $1.5-2.0 \mathrm{~m}$ tall. At this time, natural rainfall had to some extent sealed the soil surface in both conservation and conventional fields. Measurements were done using standard double ring infiltrometers delivered by Eijkelkamp Soil and Water with an inner ring diameter of $30 \pm 2 \mathrm{~cm}$. Since riplines and basins were about $15 \mathrm{~cm}$ wide, the inner infiltration ring covered up to $7.5 \mathrm{~cm}$ of non-ripped or non-basin soil on either side of the rows. Infiltration 'in rows' and 'in basins' was done in spots where maize plants had not germinated. Readings of float levels were made every minute for $60 \mathrm{~min}$ with three replicas. A specially designed padding was placed on the soil surface inside the rings to prevent soil disturbance during filling of the rings. The experiment consumed in total about 25,000 L of water for all three regions. Best-fit power functions for mean infiltration rates were calculated using Microsoft Excel.

Soil moisture was measured weekly throughout the 2013/14 and 2014/15 seasons from the onset of the first consistent rain until the soils became too dry for measurements at the end of the season. Dates for start and stop of measurement varied slightly between fields and regions based on local rainfall. Sites for the initial measurements were selected purposively and semi-randomly, as described above. Replicate measurements were made in the vicinity of the first sites about 1-2 $\mathrm{m}$ away from earlier auger holes. Measurements were done at least $30 \mathrm{~cm}$ from the nearest maize plant to reduce the effect of direct uptake of water by plants [31]. Soil moisture was measured using a ThetaProbe Soil Moisture Sensor Type ML2x connected to a Soil Moisture Meter HH2 delivered by Eijkelkamp Soil and Water. The ThetaProbe was attached to a $150-\mathrm{cm}$ plastic tube for readings at six soil depths from $0-10 \mathrm{~cm}$ to $50-60 \mathrm{~cm}$ or to the depth possible using a soil auger. Calculations of mean soil moisture in ripped fields and fields with basins were made with the assumption that the moisture measurements recorded 'in ripline' and 'in basin' applied to a width of $15 \mathrm{~cm}$ across plant rows at $0-10 \mathrm{~cm}$ soil depth and increasing gradually to $30 \mathrm{~cm}$ width at $50-60 \mathrm{~cm}$ soil depth. Readings were done weekly with four replicas constituting a total of about 34,000 measurements over two seasons. 
Rainfall was recorded by simple rainfall gauges mounted about $2 \mathrm{~m}$ above ground in spots that were unaffected by trees or buildings. Readings were done weekly on the same weekday as soil moisture readings.

All measurements were made pairwise on conservation and conventional fields situated close to one another (mostly from $50 \mathrm{~m}$ to $500 \mathrm{~m}$ apart). Data analyses were done pairwise to minimize effects of differences in soil type, slope, and local rainfall events. Results are presented as ratios for each pair of conservation tillage over conventional tillage. Calculations of mean ratios were made on the basis of $\log$ of measured values.

\section{Conclusions}

The selected 'best conservation farmers' and 'best conventional farmers' retained similar and low amounts of soil cover in their fields. Conservation-tilled fields showed consistently shorter time for start of surface water saturation, start of ponding, and start of runoff under artificial rain compared to conventional fields. Conventionally tilled fields had a higher weighted average water infiltration rate than the conservation-tilled fields. Riplines and planting basins contained more moisture than ploughed/ridged soil early in the season. The difference disappeared or became smaller later in the season. Soil between riplines and basins contained less moisture than ploughed/ridged soil throughout the season, particularly during the middle and late part of the season. Overall, conservation fields contained on average $8.5 \%$ less moisture in the root zone $(0-60 \mathrm{~cm}$ soil depth) than conventional fields over two seasons. The results of this study do, therefore, not support the common notion that conservation tillage, as practiced by small-scale farmers, is more 'climate smart' than conventional tillage in terms of soil water conservation. On the contrary, minimum tillage combined with little or no soil cover appear to have a negative effect on soil moisture. Inconsistencies between these results and results from earlier studies under controlled conditions are apparently caused by differences in soil cover. Low retention of plant residues in fields of farmers classified as 'adopters of conservation agriculture' leads to the development of soil surface crust between riplines and basins and consequently reduced water infiltration.

Acknowledgments: This study was part of the Conservation Agriculture Research and Evaluation Programme (CAREP) funded by the Norwegian Ministry of Foreign Affairs through the Conservation Farming Unit (CFU), Zambia. The author thanks field officers Nigel J. Mumba, Canaan K. Sibanda, Cain Mweemba, Silvanho S. Twaambo, Raymond Syandebwe, and Penias Tembo for their tireless collection of extensive field data and for inputs to data interpretation. The author also thanks farmers Lucy Mpofu, Ernest Tabengelwa, Bornwell Shambwalu, Albert Dandazi, Jatto Simpelwe, Phanuel Jere, Watson Kawelele, Chief of Kabulwebulwe, George Banda, Royce Shamwinde, Jeremia Kabanza (Mumbwa area), Octovious Moonga, Naomi Mweetwa, Vaddy Muzungu, Macman Hamando, Charles Malambo, Ilukena Mutumba, Paul Milimo, Kebby Mweemba, Richard Butts (Monze area), Bernardent Phiri, Jenifer Banda, Lackson Banda, Lawrence Kamanga, Peter Miti, Brighton Phiri, Samuel Banda, and Rodgers Banda (Chipata area) for permission to collect data on their farms, assistance with data recording and water collection, and for valuable information aiding the interpretation of results.

Conflicts of Interest: The author declares no conflict of interest. The funding sponsors had no role in the design of the study; in the collection, analyses, or interpretation of data; in the writing of the manuscript, and in the decision to publish the results.

\section{References}

1. Verhulst, N.; Govaerts, E.; Verachtert, E.; Castellanos-Navarrete, A.; Mezzalama, M.; Wall, P.C.; Chocobar, A.; Deckers, J.; Sayre, K.D. Conservation agriculture, improving soil quality for sustainable production systems? In Advances in Soil Science: Food Security and Soil Quality; Lal, R., Stewart, B.A., Eds.; CRC Press: Boca Raton, FL, USA, 2010; pp. 137-208.

2. Kahlon, M.S.; Lal, R.; Ann-Vaughese, M. Twenty two years of tillage and mulching impacts on soil physical characteristics and carbon sequestration in Central Ohio. Soil Till. Res. 2013, 126, 151-158. [CrossRef]

3. Palm, C.; Blanco-Canqui, H.; de Clerck, F.; Gatere, L.; Grace, P. Conservation agriculture and ecosystem services: An overview. Agric. Ecosyst. Environ. 2014, 187, 87-105. [CrossRef] 
4. Food and Agriculture Organization of the United Nations (FAO). Climate-Smart Agriculture: Sourcebook; Food and Agriculture Organization of the United Nations: Rome, Italy, 2013; pp. 203-204.

5. Roth, C.H.; Meyer, B.; Frede, H.-G.; Derpsch, R. Effect of mulch rates and tillage systems on infiltrability and other soil physical properties of an Oxisol in Paraná, Brazil. Soil Till. Res. 1988, 11, 81-91. [CrossRef]

6. LeBissonnais, Y. Aggregate stability and assessment of soil crustability and erodibility: I. Theory and methodology. Eur. J. Soil Sci. 1996, 47, 425-437. [CrossRef]

7. Li, H.W.; Gao, H.W.; Wu, H.D.; Li, W.Y.; Wang, X.Y.; He, J. Effects of 15 years of conservation tillage on soil structure and productivity of wheat cultivation in northern China. Aust. J. Soil Res. 2007, 45, 344-350. [CrossRef]

8. Mulumba, L.N.; Lal, R. Mulching effects on selected soil phisical properties. Soil Till. Res. 2008, 98, $106-111$. [CrossRef]

9. Singh, B.; Malhi, S.S. Response of soil physical properties to tillage and residue management on two soils in a cool temperate environment. Soil Till. Res. 2006, 85, 143-153. [CrossRef]

10. Materechera, S.A.; Mloza-Banda, H.R. Soil penetration resistance, root growth and yield of maize as influenced by tillage system on ridges in Malawi. Soil Till. Res. 1997, 41, 13-24. [CrossRef]

11. Lal, R.; Eckert, D.J.; Fausey, N.R.; Edwards, W.M. Conservation agriculture in sustainable agriculture. In Sustainable Agricultural Systems; Edwards, C.A., Lal, R., Madden, P., Miller, R.H., House, G., Eds.; St. Lucie Press: Boca Raton, FL, USA, 1990; pp. 203-225.

12. Thierfelder, C.; Mwila, M.; Rusinamhodzi, L. Conservation agriculture in Eastern and Southern Provinces of Zambia: Long-term effects on soil quality and maize productivity. Soil Till. Res. 2013, 126, 246-258. [CrossRef]

13. Corbeels, M.; de Graaff, J.; Ndah, T.H.; Penot, E.; Baudron, F.; Naudin, K.; Andrieu, N.; Chirat, G.; Schuler, J.; Nyagumbo, I.; et al. Understanding the impact and adoption of conservation agriculture in Africa: A multi-scale analysis. Agric. Ecosyst. Environ. 2014, 187, 155-170. [CrossRef]

14. Richardson, R.B.; Olabisi, L.S.; Sakana, N.; Waldman, K.; Grabowski, P. The Impact of Sustainable Intensification on Landscapes and Livelihoods (SILL) in Zambia; International Institute of Tropical Agriculture: Ibadan, Nigeria, 2015; pp. 4-6.

15. Nyanga, P. Factors influencing adoption and area under conservation agriculture: A mixed methods approach. Sust. Agric. Res. 2012, 1, 27-40. [CrossRef]

16. Arslan, A.; McCarthy, N.; Lipper, L.; Asfaw, S.; Cattaneo, A. Adoption and intensity of adoption of conservation farming practices in Zambia. Agric. Ecosyst. Environ. 2014, 187, 72-86. [CrossRef]

17. Zambia Conservation Agriculture Programme (CAP)—A Brief Update. Available online: https: / 八discretionary\{-\}\{\}\{\}vtechworks.lib.vt.edu/bitstream/handle/10919/69066/4836_Zambia_CAP.pdf? sequence $=1 \&$ is Allowed $=y$ (accessed on 26 August 2016).

18. Interannual Variation of Seasonal Rainfall in South Zambia. Available online: http://www.chikyu. $\backslash$ discretionary\{-\}\{\}\{\}ac.jp/resilience/files/ReportFY2010/ResilienceProject_Report2010_25.pdf (accessed on 28 May 2014).

19. Chabala, L.M.; Kuntashula, E.; Kaluba, P. Characterization of temporal changes in rainfall, temperature, flooding hazard and dry spells over Zambia. Univers. J. Agric. Res. 2013, 1, 134-144.

20. Esser, K.B.; Nyanga, P.H.; Mumba, N.J.; Mweemba, C.; Penias, T.; Sibanda, C.K.; Syandebwe, R.; Twaambo, S. Effects of conservation agriculture on maize growth and yields in the 2013/14 season. In Conservation Agriculture Research and Evaluation Programme 2012-2015, Zambia (CAREP): Final Report; Esser, K.B., Ed.; Norwegian University of Life Sciences: Ås, Norway, 2016; pp. 60-70.

21. Esser, K.B.; Mumba, N.J.; Mweemba, C.; Sibanda, C.K.; Twaambo, S.; Syandebwe, R.; Penias, T. Agro-economic effects of recommended conservation agriculture as perceived and implemented by leading farmers; 2014/15 season. In Conservation Agriculture Research and Evaluation Programme 2012-2015, Zambia (CAREP): Final Report; Esser, K.B., Ed.; Norwegian University of Life Sciences: Ås, Norway, 2016; pp. 71-97.

22. Sibanda, C.; Mumba, N.J.; Esser, K.B. Farmer evaluation of results from the agro-economic study and their appraisal of farming challenges, 2014/15 season. In Conservation Agriculture Research and Evaluation Programme 2012-2015, Zambia (CAREP): Final Report; Esser, K.B., Ed.; Norwegian University of Life Sciences: Ås, Norway, 2016; pp. 98-116. 
23. Baudron, F.; Tittonell, P.; Corbeels, M.; Letourmy, P.; Giller, K.E. Comparative performance of conservation agriculture and current smallholder farming practices in semi-arid Zimbabwe. Field Crops Res. 2012, 132, 117-128. [CrossRef]

24. Zambia: Description of Cropping Systems, Climate, and Soils in Zambia. Global Yield Gap Atlas. Available online: http:/ / www.yieldgap.org/zambia (accessed on 10 May 2016).

25. World Climate \& Temperature. Available online: http://www.zambia.climatemps.com (accessed on 15 September 2014).

26. FAO and UNESCO. Soil Map of Zambia. Available online: http://eusoils.jrc.ec.europa.eu/esdb_archive/ eudasm/africa/maps/afr_zm20011_so.htm (accessed on September 2014).

27. FARA. Agro-ecological zones of Zambia. Available online: http://www.erails.net/ZM/kms-zambia/kmszambia/agro-ecological-zones / (accessed on 10 February 2017).

28. Pannell, D.J.; Marshall, G.R.; Barr, N.; Curtis, A.; Vanclay, F.; Wilkinson, R. Understanding and promoting adoption of conservation practices by rural landholders. Aust. J. Exp. Agric. 2006, 46, 1407-1424. [CrossRef]

29. Patton, M.Q. Qualitative Research and Evaluation Methods, 4th ed.; SAGE Publications Inc.: Thousand Oaks, CA, USA, 2002; pp. 264-272, 305-307.

30. Saunders, M.; Lewis, P.; Thornhill, A. Research Methods for Business Students, 6th ed.; Pearson Education Ltd.: Essex, UK, 2012; pp. 287-289.

31. Esser, K.B. Hardpan and maize root distribution under conservation and conventional tillage in Agro-ecological Zone IIa, Zambia. Afr. Crop Sci. J. 2016, 24, 267-287. [CrossRef]

32. The University of Zambia (UNZA). Practical Manual for Fundamentals of Soil Science, 3rd ed.; (2014/2015 update); Soil Science Department, School of Agricultural Sciences, University of Zambia: Lusaka, Zambia, 1998.

(C) 2017 by the author. Licensee MDPI, Basel, Switzerland. This article is an open access article distributed under the terms and conditions of the Creative Commons Attribution (CC BY) license (http:/ / creativecommons.org/licenses/by/4.0/). 